\title{
Article \\ Quantitative Phase Dynamics of Cancer Cell Populations Affected by Blue Light
}

\author{
Marek Feith ${ }^{1,2}{ }^{\circledR}$, Tomáš Vičar ${ }^{1,3}$, Jaromír Gumulec ${ }^{1,4,5}$, Martina Raudenská ${ }^{1,4,5}$, \\ Anette Gjörloff Wingren 2,6(1), Michal Masařík ${ }^{4,5,7}$ and Jan Balvan ${ }^{4, *}$ (i)
}

1 Department of Physiology, Faculty of Medicine, Masaryk University, 62500 Brno, Czech Republic; mafeith@seznam.cz (M.F.); xvicar@gmail.com (T.V.); j.gumulec@med.muni.cz (J.G.); m.raudenska@gmail.com (M.R.)

2 Department of Biomedical Sciences, Faculty of Health and Society, Malmö University, 21428 Malmö, Sweden; anette.gjorloff-wingren@mau.se

3 Department of Biomedical Engineering, Faculty of Electrical Engineering and Communication, Brno University of Technology, 61600 Brno, Czech Republic

4 Department of Pathophysiology, Faculty of Medicine, Masaryk University, 62500 Brno, Czech Republic; masarik@med.muni.cz

5 Department of Chemistry and Biochemistry, Mendel University in Brno, Zemedelska 1, CZ-613 00 Brno, Czech Republic

6 Biofilms Research Center for Biointerfaces, Malmö University, 21428 Malmö, Sweden

7 BIOCEV, First Faculty of Medicine, Charles University, Prumyslova 595, 25250 Vestec, Czech Republic

* Correspondence: jan.balvan@med.muni.cz

Received: 12 March 2020; Accepted: 4 April 2020; Published: 9 April 2020

Featured Application: Quantitative phase imaging (QPI) and holographic microscopy (HM) are suitable methods for long-term and label-free imaging of cells and for the complex evaluation of cellular morphological and dynamical parameters under different treatments. Our results suggest that HM within advanced image analysis is capable of correctly distinguishing between subtle changes in cell motility, cell dry mass, cell density, and cell death induced by blue light. As quantitative phase dynamics of the cell population is typical for specific processes in cells, it may be useful for viability tests and medical drugs evaluation. In particular, mapping of the quantitative phase changes during the time seems to be very promising in the determination of various morphological phenomena related to cell death, because the responsible cell death molecular machinery typically changes the distribution of the cell mass.

Abstract: Increased exposition to blue light may induce many changes in cell behavior and significantly affect the critical characteristics of cells. Here we show that multimodal holographic microscopy (MHM) within advanced image analysis is capable of correctly distinguishing between changes in cell motility, cell dry mass, cell density, and cell death induced by blue light. We focused on the effect of blue light with a wavelength of $485 \mathrm{~nm}$ on morphological and dynamical parameters of four cell lines, malignant PC-3, A2780, G361 cell lines, and the benign PNT1A cell line. We used MHM with blue light doses $24 \mathrm{~mJ} / \mathrm{cm}^{2}, 208 \mathrm{~mJ} / \mathrm{cm}^{2}$ and two kinds of expositions (500 and $1000 \mathrm{~ms}$ ) to acquire real-time quantitative phase information about cellular parameters. It has been shown that specific doses of the blue light significantly influence cell motility, cell dry mass and cell density. These changes were often specific for the malignant status of tested cells. Blue light dose $208 \mathrm{~mJ} / \mathrm{cm}^{2} \times 1000 \mathrm{~ms}$ affected malignant cell motility but did not change the motility of benign cell line PNT1A. This light dose also significantly decreased proliferation activity in all tested cell lines but was not so deleterious for benign cell line PNT1A as for malignant cells. Light dose $208 \mathrm{~mJ} / \mathrm{cm}^{2} \times 1000 \mathrm{~ms}$ oppositely affected cell mass in A2780 and PC-3 cells and induced different types of cell death in A2780 and G361 cell lines. Cells obtained the least damage on lower doses of light with shorter time of exposition. 
Keywords: holographic microscopy; quantitative phase imaging; blue light; cell mass; cell motility; cell death

\section{Introduction}

Natural light is essential for the adjustment of circadian clocks and the coordination of cellular physiology. Nevertheless, emerging evidence suggests that increased exposure to artificial light can significantly influence important characteristics of cells. It has been shown that blue light at lower doses $\left(\leq 300 \mathrm{~mJ} / \mathrm{cm}^{2}\right)$ triggers the synthesis of hydrogen peroxide in T-cells and affects cell motility [1]. Other studies suggest that blue light changes the redox state of the cell causing oxidative stress and alter mitochondrial activity [2,3] or that green light can change gene expression [4]. As recent technological advances brought televisions, LEDs, and displays, blue light emitters have become a part of our everyday life and blue light is also used for polymerization of dental resin in dentistry [5], its effect on the behavior of cells should be deeply studied. Studies on model organisms suggest that visible light can exert a range of detrimental effects. For example, a single acute blue light exposure causes cell death of photoreceptors in the retina of mice and flies [6,7]. Blue light is also used in photodynamic therapy (PDT) of cancer. PDT represents an important treatment approach as it uses a photosensitizer and visible light to induce reactive oxygen species (ROS) to kill cancer cells [8,9]. For example, Sullivan et al. have reported the antitumor effect of an agent dequalinium and light of a $366 \mathrm{~nm}$ wavelength. A combination of specific light and an agent inhibits protein kinase $C$ and induces inhibition of metastatic behavior of melanoma cells [10]. However, the effects of blue light itself on the essential characteristic of cancer cells, such as motility or cell division is not known.

The light with $488 \mathrm{~nm}$ is commonly used as an excitation light in fluorescence microscopy (FM) which allows precise imaging of cellular structures or even certain molecules in cells [11,12]. Despite the widespread of FM in cell research in the last 40 years, the impact of such techniques on basic cell features was not well characterized yet. In this study, we focused on the effect of light with $485 \mathrm{~nm}$ wavelength on the dynamical and morphological properties of the three human cancer cell lines established from different tissue (PC-3, A2780, G361) and one non-malignant human prostate cell line (PNT1A), respectively. In our experiments, we use a multimodal holographic microscope (MHM) that combines holographic microscopy with fluorescence microscopy. The MHM used in this study is based on an off-axis setup with an incoherent source of light which enables high-quality quantitative phase imaging, avoiding disruptive interferences [13]. Holographic microscopy (HM) has been demonstrated as a powerful tool for long-term and label-free imaging of cell samples in vitro, as it works on the principle of quantitative phase imaging (QPI). HM provides information about many cellular processes and parameters such as cell cycle [14], cell kinetic [15], viability [16], cell morphology [17], and cellular uptake [18]. This approach enables also to measure cell mass and its distribution in cells [19-21]. Based on QPI, a new approach of distinction of apoptosis and lytic types of cell death was developed [22,23]. HM also enables effort-less and more accurate tracking of cells and their motility patterns compared to other microscopic techniques [24,25]. Our study aims to present QPI and holographic microscopy as a suitable method for the evaluation of cellular morphological and dynamical parameters. The results suggest that $\mathrm{HM}$ within advanced image analysis is capable of correctly distinguishing between changes in cell motility, cell dry mass, cell density, and cell death induced by blue light and that the impact of light is dependent on the exposure time and light intensity.

\section{Materials and Methods}

\subsection{Chemical and Biochemical Reagents}

RPMI-1640 medium, Ham's F-12 medium, penicillin/streptomycin, fetal bovine serum (FBS) (mycoplasma-free), ethylenediaminetetraacetic acid (EDTA), were purchased from Sigma Aldrich Co. 
(St. Louise, MO, USA). Trypsin was purchased from PAA Laboratories Gesellschaft M.B.H. (Pasching, Austria) and phosphate buffer saline (PBS) from Invitrogen Corp. (Carlsbad, CA, USA).

\subsection{Cell Lines}

The PC-3, A2780, PNT1A, and G361 cell lines were purchased from HPA Culture Collections (Salisbury, UK). PC-3 prostate cancer cell line was derived from bone metastasis of a 4-grade prostatic adenocarcinoma of a 62-year-old Caucasian male [26]. The A2780 cell line was derived from the ovarian carcinoma of a nontreated patient according to ECACC. PNT1A cell line was established from prostatic epithelial tissue of healthy 35-years old male and immortalized by plasmid transfection containing the SV40 genome with defective replication origin $[27,28]$. The G361 cell line was established from a malignant melanoma of a 31-year-old male Caucasian. The G361 cells produce melanin for up to 50 population doublings. As the aim of this study is to compare the effect of blue light on the cell lines differing by morphology, transformation state, sensitivity to cell death, and origin, we decided to use the cell lines listed above. PC-3 cells are larger in comparison with small A2780 cells. Benign PNT1A cell line differs from malignant PC-3, and all four cell lines are derived from diverse tissues of origin. Furthermore, melanoma G361 cells expressing melanin may differ in the reaction of cells to blue light exposure.

\subsection{Cell Cultivation}

All four cell lines were cultivated in $25 \mathrm{~cm}^{2}$ flasks with $5 \mathrm{ml}$ of media at $37^{\circ} \mathrm{C}$ in a humidified incubator $(60 \%)$ with 5\% $\mathrm{CO}_{2}$ (Sanyo, Osaka City, Japan). Cell lines A2780, PNT1A and G361 were cultured in RPMI-1640 medium with phenol red indicator, L-glutamine, FBS and antibiotics penicillin/streptomycin (Sigma Aldrich Co., St. Louise, MO, USA). For the PC-3 cell line cultivation, Ham's F-12 medium with FBS and antibiotics (Sigma Aldrich Co., St. Louis, MO, USA) was used. The same supplementation with antibiotics (penicillin $100 \mathrm{U} / \mathrm{mL}$ and streptomycin $0.1 \mathrm{mg} / \mathrm{mL}$ ) and $10 \%$ FBS was used in both media. The cell medium was changed two times per week. Cell subculturing was done with $10 \%$ of trypsin solution (PAA, Pasching, Austria) with previous washing with EDTA (0.02\% in PBS buffer).

\subsection{QPI and Holographic Microscopy and Fluorescence Setting}

QPI was performed by using a Q-PHASE multimodal holographic microscope (Telight, Brno, $\mathrm{CZ}$ ). The Q-PHASE is equipped with fluorescence module using a halogen lamp as a non-coherent source of blue light. In this work, the module was used as a source of blue light for treatment of observed cell lines. The $485 \mathrm{~nm}$ light waves are emitted by the fluorescence light source of the attached module. The Q-PHASE microscope optical setup can be seen in Figure 1 of the article [22]. Before the imaging experiment, cells were cultivated overnight in a concentration of 7000 cells $/ \mathrm{mL}$ in flow chamber $\mu$-Slide I Lauer Family (Ibidi, Martinsried, Germany). During the measurements, the chamber with cells was incubated in $37^{\circ} \mathrm{C}$ humidified, $5 \% \mathrm{CO}_{2}$ atmosphere in $\mathrm{H} 201$-for Mad City Labs Z100/Z500 piezo Z-stages (Okolab, Ottaviano NA, Italy). Images and holograms were captured with lens Nikon Plan 10/0.3 and CCD camera (XIMEA MR4021 MC-VELETA, Münster, Germany) respectively. The fluorescence mode used was a plasma light source (Sutter Instrument Lambda XL Novato, CA, USA). Cells were irradiated with a $485 \mathrm{~nm}$ light with a $25 \mathrm{~nm}$ bandwidth. Light doses $0 \mathrm{~mJ} / \mathrm{cm}^{2}, 24 \mathrm{~mJ} / \mathrm{cm}^{2}$ and $208 \mathrm{~mJ} / \mathrm{cm}^{2}$ were achieved by the combination of time exposition and light intensity shown in Figure 1.

The images were acquired automatically from seven positions every $3 \mathrm{~min}$ for $24 \mathrm{~h}$. Holographic images were collected by custom software and raw data were numerically reconstructed. The numerical reconstruction was performed by custom software where the established methods of the fast Fourier-transform [29] and phase unwrapping [30,31] are implemented. The output from the software is an unwrapped phase image. This image has high intrinsic contrast and can be processed by an available image processing software. The unwrapped phase image is integrated phase shift through the cell and 
it is proportional to integrated cell dry mass density [19,32]. The values of unwrapped phase image $\varphi$ (rad) are linearly transformed into cell dry mass density image $m\left(\mathrm{pg} / \mu \mathrm{m}^{2}\right)$ with the transformation

$$
m=\frac{\varphi \lambda}{2 \pi \alpha}
$$

where $\alpha\left(0.18 \mu \mathrm{m}^{3} / \mathrm{pg}\right)$ is specific refraction increment and $\lambda(0.65 \mu \mathrm{m}$ in Q-PHASE $)$ is a wavelength, where both values are assumed to be constant. This enables measurements of cell dry mass and analysis of cell mass distribution inside cells.
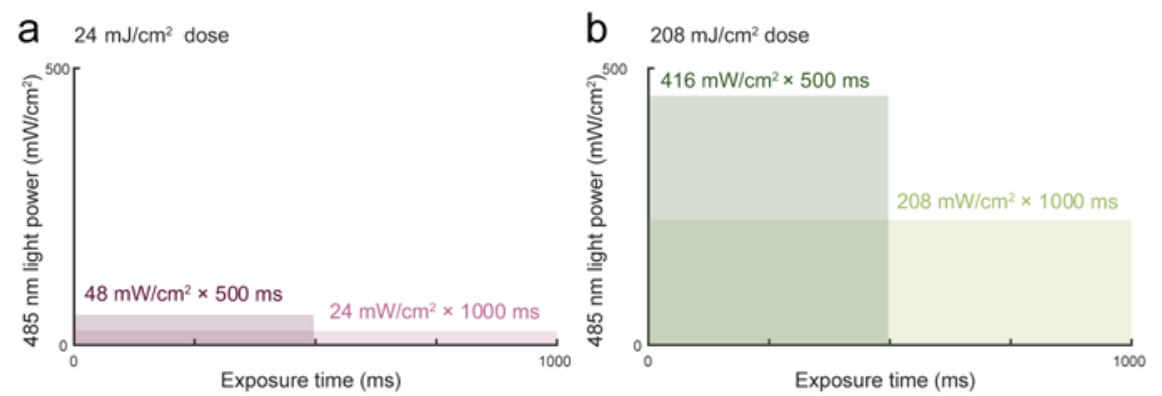

Figure 1. Blue light doses used in the experiment. Resulting blue light doses 0, 24 (a) and 208 (b) $\mathrm{mJ} / \mathrm{cm}^{2}$ were achieved by the combination of time exposition and light intensity. The intensity of fluorescence light is shown in $\mathrm{mW} / \mathrm{cm}^{2}$. Exposure time was 500 and $1000 \mathrm{~ms}$, respectively.

\subsection{Image Analysis and Statistics}

Image analysis was performed in customized Matlab R2019b (MathWorks, Natick, MA, USA) algorithm developed by our laboratory. The analysis process consists of segmentation, the interconnection of matching cells in adjacent time frames and extraction of the analyzed dynamical and morphological cell features. For cell segmentation in each frame, Loewke's Iterative Thresholding (LIT) method [33] was combined with Empirical Gradient Thresholding (EGT) technique [34]. EGT was shown to be a very robust and parameter-free foreground cell segmentation method (semantic segmentation) across various microscopical modalities [35]. On the other hand, LIT is a powerful technique for single-cell separation (instance segmentation), which is specifically designed for QPI images. LIT iteratively separates objects in "intensity valley" if the mass of separated objects is larger than the selected cell mass threshold. Our segmentation procedure is summarized in Figure 2.

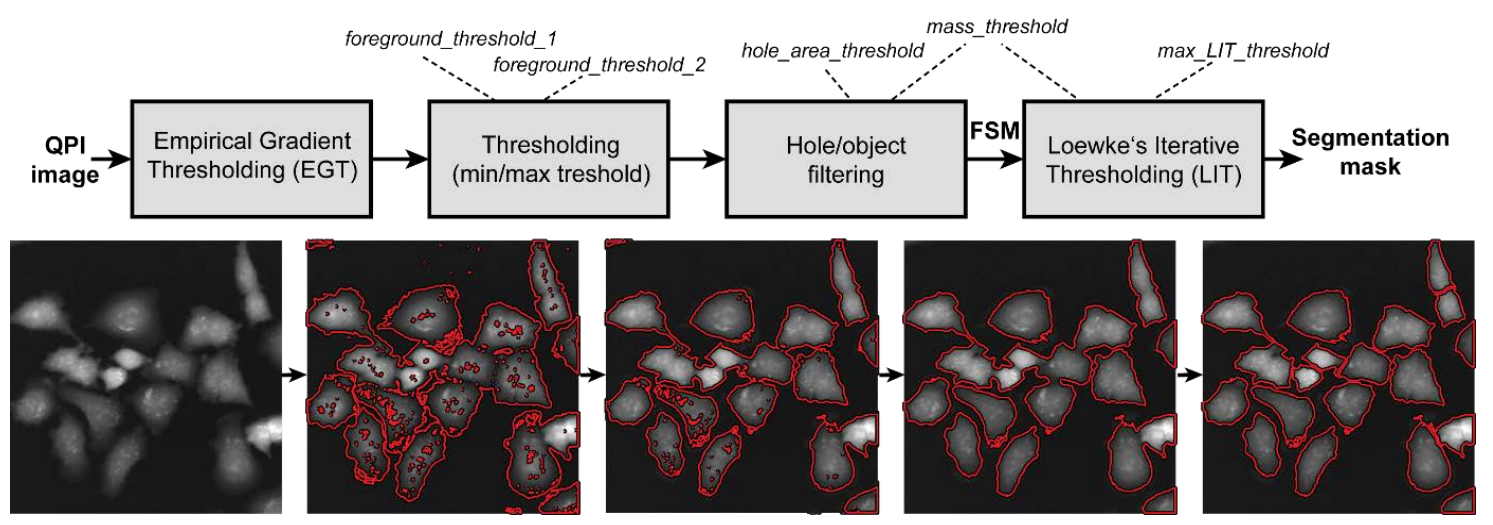

Figure 2. Block diagram of the cell segmentation algorithm. The process consists of two main steps-foreground segmentation (semantic segmentation) and single-cell separation (instance segmentation). Foreground segmentation uses EGT algorithm [34], where the result is refined with additional thresholding and object/hole filtering. Single-cell separation uses LIT algorithm [33]. Input parameters to individual steps are shown with dashed arrows. FSM, Foreground Segmentation Mask; QPI, Quantitative Phase Imaging. 
QPI image foreground can be segmented with simple thresholding; however, we found that a combination of EGT and thresholding can lead to even better results. First, EGT (with default setting) is used for foreground segmentation and its resulting foreground segmentation mask (FSM) is further improved by the inclusion of pixels brighter then foreground_threshold_1 and exclusion of pixels darker than foreground_threshold_2. Furthermore, holes smaller than hole_area_threshold and objects smaller than mass_threshold are removed.

In LIT, each grayscale foreground object masked by FSM (containing one or more cells) is iteratively thresholded, where the threshold increases in every iteration. When thresholding creates two (or more) objects and newly created objects have a larger mass than mass_threshold, they are used as new individual objects, which can be further split with the increasing threshold (and the original object will not be used). Finally, the object in FSM is separated by watershed lines, which are created by the application of the watershed algorithm [36] on Euclidean distance transform [37] of masks of objects created with thresholding. In original LIT [33], threshold grows until it reaches maximum image intensity, which leads to over-segmentation in some cases, thus we have introduced a maximal_LIT_threshold parameter and iterations are stopped when the threshold reaches this value.

Parameters foreground_threshold_1, foreground_threshold_2 and maximal_LIT_threshold were set for all cell lines to value $0.07,0.4$ and 2, respectively. Hole_area_trehold and mass_treshold were manually adjusted for each cell line (but stay fixed for all light doses).

Sufficiently, precise tracking of individual cells during the whole sequence is a very hard problem [23]; however, for analysis of our dynamical features statistics across the whole-cell set, we require only to correctly cross-connect cells between each two consecutive time frames and larger tracks are not required. This was achieved by searching for the largest overlap with respect to Intersection over Union (IoU) of segmentation masks, where everything with IoU smaller than 0.7 was discarded as segmentation errors or cell divisions and thus these cells were not used for calculation of dynamical features. As dynamical features describing cell motility, we have extracted cell speed (Euclidian distance between cell centroid in two consecutive frames) and Cell Dynamic Score (CDS) defined in [23] (Euclidean distance of cell pixel values in two consecutive frames). Cell dry mass and cell density are calculated as a sum and a mean of cell pixel values, respectively.

Statistics was performed in R version 3.6.1 (R Core Team, 2020) [38] using ggpubr 0.2.4 (CRAN, 2020) package [39] with Wilcoxon test. Unless noted otherwise, $p$ level $<0.05$ was considered significant.

\section{Results}

\subsection{Blue Light Dose $208 \mathrm{~mJ} / \mathrm{cm}^{2}, 1000 \mathrm{~ms}$ Affects Malignant Cell Motility and Does Not Change Motility of Benign Cell Line PNT1A}

The motility of PC-3, A2780, PNT1A, and G361 cells was measured by using Q-PHASE multimodal holographic microscope. It was shown that light dose $208 \mathrm{~mJ} / \mathrm{cm}^{2} \times 1000 \mathrm{~ms}$ affected the motility of all types of malignant cells-PC-3, A2780, G361 (Figure 3). A2780 cells showed a distinctive decrease of motility from the beginning of the measurement while PC-3 and G361 cells decreased their motility after 15 and $20 \mathrm{~h}$ of measurement, respectively. The benign cell line PNT1A showed no motility changes in comparison with control by using light dose $208 \mathrm{~mJ} / \mathrm{cm}^{2} \times 1000 \mathrm{~ms}$. The most intense light dose $208 \mathrm{~mJ} / \mathrm{cm}^{2} \times 500 \mathrm{~ms}$ decreased motility of all cell lines with the most visible effect on PNT1A and A2780 cells. Some effect was also observed in the PC-3 cells with blue light dose $24 \mathrm{~mJ} / \mathrm{cm}^{2} \times 500 \mathrm{~ms}$. 

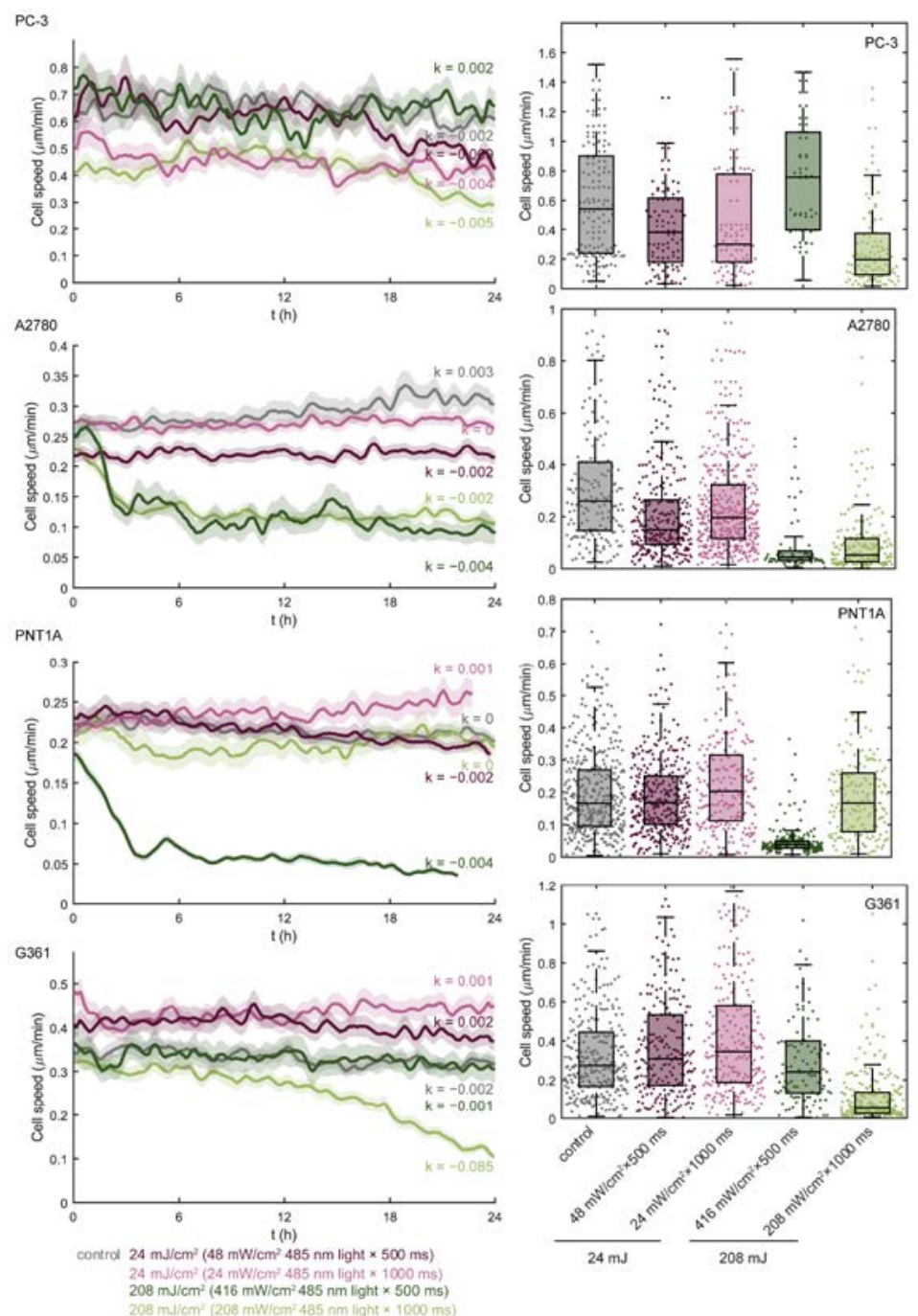

Figure 3. Real-time QPI-measured motility of cells affected by different doses of blue light. Real-time motility of PC-3, A2780, PNT1A, and G361 cells during $24 \mathrm{~h}$ of the experiment (left side of the figure). Lines are shown as the mean and standard error. $\mathrm{K}$ value means the slope of the least-square fitted line (increment of the value per hour). The end-point motility values of PC-3, A2780, PNT1A, and G361 cells after $24 \mathrm{~h}$ exposure to blue light (right side of the figure). Boxes are composed of the main box edges (25th and 75th percentile), central line (median) and whiskers (lowest and highest value of 1.5 of inter-quartile range).

\subsection{Blue Light Doses $208 \mathrm{~mJ} / \mathrm{cm}^{2}, 1000 \mathrm{~ms}$ Significantly Decrease Proliferation Activity in All Tested Cell Lines}

The relative number of cells obtained by QPI was compared with the number of cell divisions manually counted from videos edited in Image $1.49 \mathrm{v}(\mathrm{NIH}$, USA and recalculated according to the length of the experiment. All control cells have positive rates of proliferation during the experiment. Although some light doses such as $24 \mathrm{~mJ} / \mathrm{cm}^{2} \times 500 \mathrm{~ms}$ in A2780 and PC-3 cells showed some proliferative effects, these effects had no statistical significance (Figure 4). The light dose of $208 \mathrm{~mJ} / \mathrm{cm}^{2}$ $\times 1000 \mathrm{~ms}$ negatively affected proliferation in all cell lines. Interestingly, this light dose was not so deleterious for benign cell line PNT1A as for malignant cells (Supplementary Videos S1-S4). The least harmful dose in our cells was $24 \mathrm{~mJ} / \mathrm{cm}^{2} \times 500 \mathrm{~ms}$. 

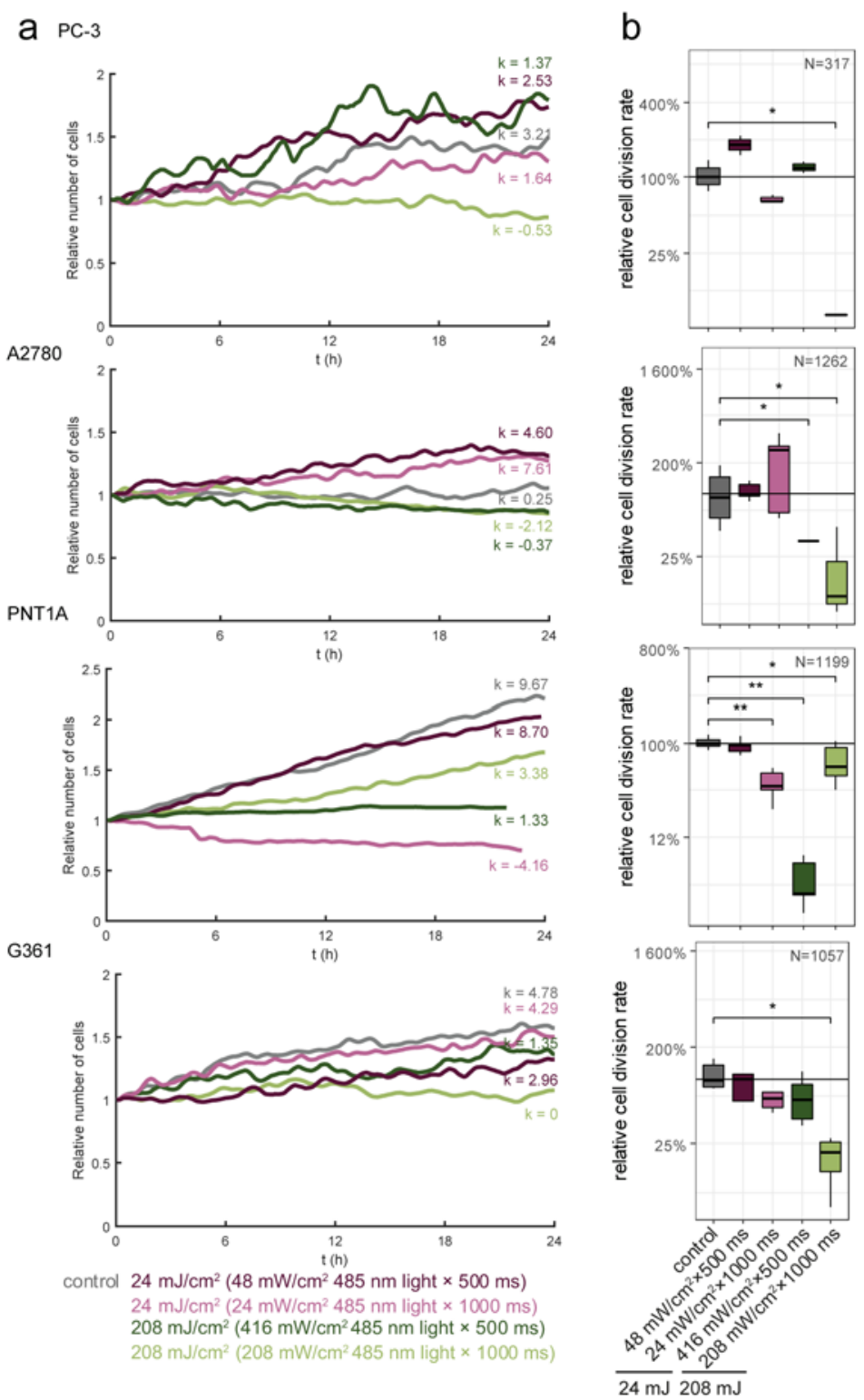

Figure 4. Cell numbers and cell division rate of cells affected by different doses of blue light. (a) Real-time QPI-measured changes in cell numbers of PC-3, A2780, PNT1A, and G361 cells during $24 \mathrm{~h}$ of the experiment. Lines are shown as the mean and standard error. K value means the slope of the least-square fitted line (increment of the value per hour). (b) Cell division rate relative to the division rate of control cells. ${ }^{*}$ indicate $p<0.05,{ }^{* *} p<0.01$ by Wilcoxon test. The number of cells (N) shown for all treatments in a timepoint 0 .

\subsection{Light Dose $208 \mathrm{~mJ} / \mathrm{cm}^{2} \times 1000 \mathrm{~ms}$ Oppositely Affects Cell Mass in A2780 and PC-3}

While cell mass in A2780 decreased quickly after exposure to blue light dose $208 \mathrm{~mJ} / \mathrm{cm}^{2} \times$ $1000 \mathrm{~ms}$, the cell mass in PC-3 continually increased (Figure 5). These changes in cell dry mass (Figure $5 \mathrm{a}, \mathrm{b}$ ) and the decrease of the relative number of A2780 cells (Figure 4) indicate cell death in this cell line [23]. Indeed, a high rate of cell death was shown in the A2780 cell line under these conditions (Supplementary Video S2). On the other hand, the number of PC-3 cells during the 24 h-effect of light dose $208 \mathrm{~mJ} / \mathrm{cm}^{2} \times 1000 \mathrm{~ms}$ was not significantly changed and an increase in cell dry mass indicates anabolic processes in this cell line (Supplementary Video S3).

The opposite effect on cell dry mass in these cell lines was also shown as a result of light dose $208 \mathrm{~mJ} / \mathrm{cm}^{2} \times 500 \mathrm{~ms}$ but was not so profound as with dose $208 \mathrm{~mJ} / \mathrm{cm}^{2} \times 1000 \mathrm{~ms}$. 
a

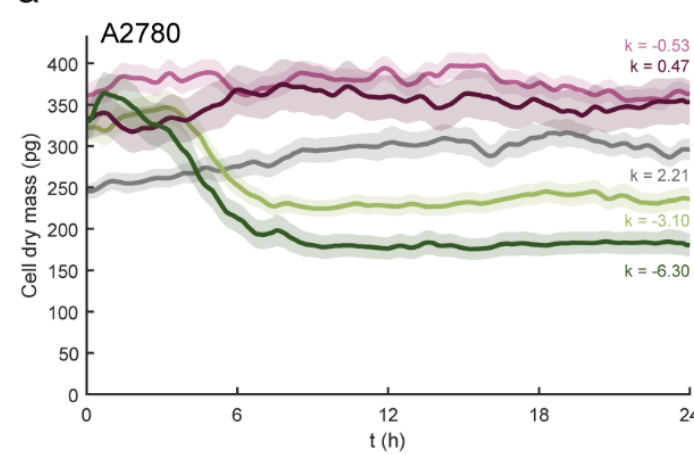

control $24 \mathrm{~mJ} / \mathrm{cm}^{2}\left(48 \mathrm{~mW} / \mathrm{cm}^{2} 485 / 25 \mathrm{~nm}\right.$ light $\left.\times 500 \mathrm{~ms}\right)$ $24 \mathrm{~mJ} / \mathrm{cm}^{2}\left(24 \mathrm{~mW} / \mathrm{cm}^{2} 485 / 25 \mathrm{~nm}\right.$ light $\left.\times 1000 \mathrm{~ms}\right)$ $208 \mathrm{~mJ} / \mathrm{cm}^{2}\left(416 \mathrm{~mW} / \mathrm{cm}^{2} 485 / 25 \mathrm{~nm}\right.$ light $\left.\times 500 \mathrm{~ms}\right)$

C

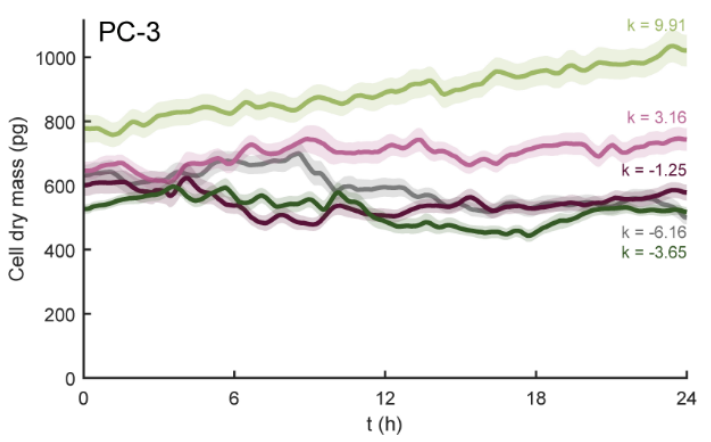

control $24 \mathrm{~mJ} / \mathrm{cm}^{2}\left(48 \mathrm{~mW} / \mathrm{cm}^{2} 485 \mathrm{~nm}\right.$ light $\left.\times 500 \mathrm{~ms}\right)$ $24 \mathrm{~mJ} / \mathrm{cm}^{2}\left(24 \mathrm{~mW} / \mathrm{cm}^{2} 485 \mathrm{~nm}\right.$ light $\left.\times 1000 \mathrm{~ms}\right)$ $208 \mathrm{~mJ} / \mathrm{cm}^{2}\left(416 \mathrm{~mW} / \mathrm{cm}^{2} 485 \mathrm{~nm}\right.$ light $\times 500 \mathrm{~m}$ $208 \mathrm{~mJ} / \mathrm{cm}^{2}\left(208 \mathrm{~mW} / \mathrm{cm}^{2} 485 \mathrm{~nm}\right.$ light $\left.\times 1000 \mathrm{~ms}\right)$ b
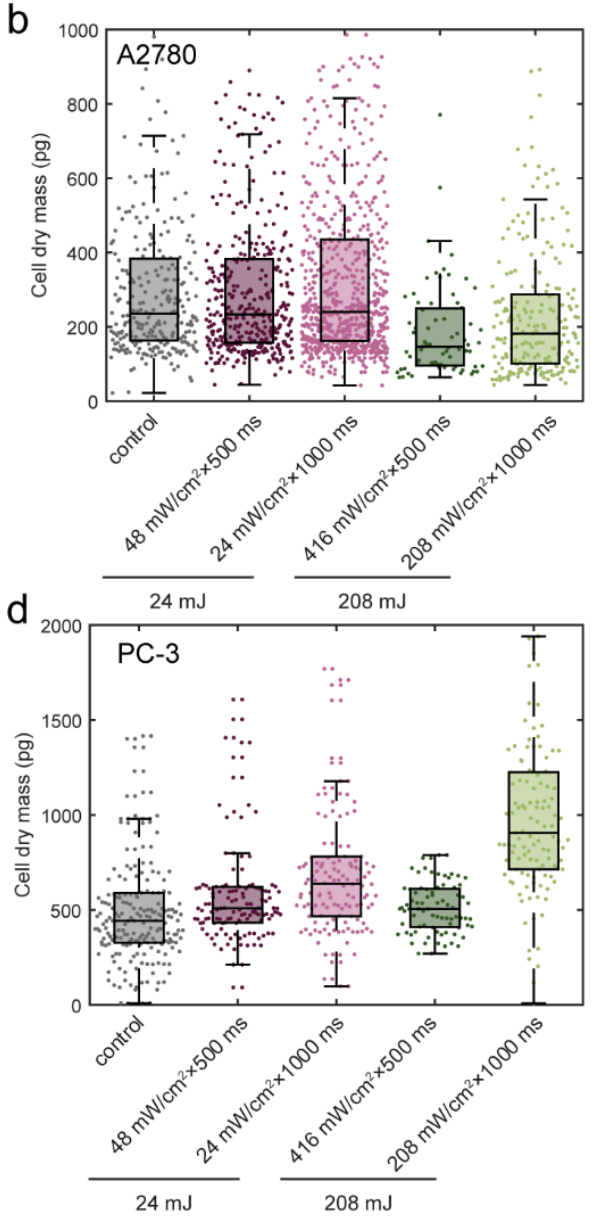

Figure 5. Real-time QPI-measured dry mass of cells affected by different doses of blue light. (a) Real-time changes in dry mass of A2780 cells during $24 \mathrm{~h}$ of the experiment. (b) The end-point dry mass values of A2780 cells after 24 h-exposure to blue light. (c) Real-time changes in dry mass of PC-3 cells during $24 \mathrm{~h}$ of the experiment. (d) The end-point dry mass values of PC-3 cells after $24 \mathrm{~h}$-exposure to blue light. Bar charts are shown as the mean and standard error. Lines are shown as the mean and standard error. K value means the slope of the least-square fitted line (increment of the value per hour). Boxes are composed of the main box edges (25th and 75th percentile), central line (median) and whiskers (lowest and highest value of 1.5 of inter-quartile range).

\subsection{Different Types of Cell Death Are Induced by Blue Light in A2780 and G361 Cell Lines}

The high numbers of cell deaths were observed in cell lines A2780 and G361 after exposure to blue light dose $208 \mathrm{~mJ} / \mathrm{cm}^{2} \times 1000 \mathrm{~ms}$ (Supplementary Videos S2 and S4). Nevertheless, these cell deaths were morphologically different. The type of cell death in G361 was characteristic by a gradual cell rounding and a loss of surface contact followed by intensive membrane blebbing. The type of cell death in A2780 involved persisting large cytoplasmic membrane blebs or multiple small blebs and cell swelling leading to the final cell membrane rupture. While the cell death in G361 cells (bona fide apoptosis) showed an increase in cell density, relatively stable cell dry mass, and strong fluctuation in average intensity change of cell pixels further designated as Cell Dynamic Score (CDS), during the cell death in A2780 cells (bona fide necrosis) the cell density was low, cell dry mass steeply decreased, and CDS was relatively stable after the initial decline (Figure 6). We have previously published these cell deaths induced by staurosporine and doxorubicin treatment elsewhere [23]. 
a
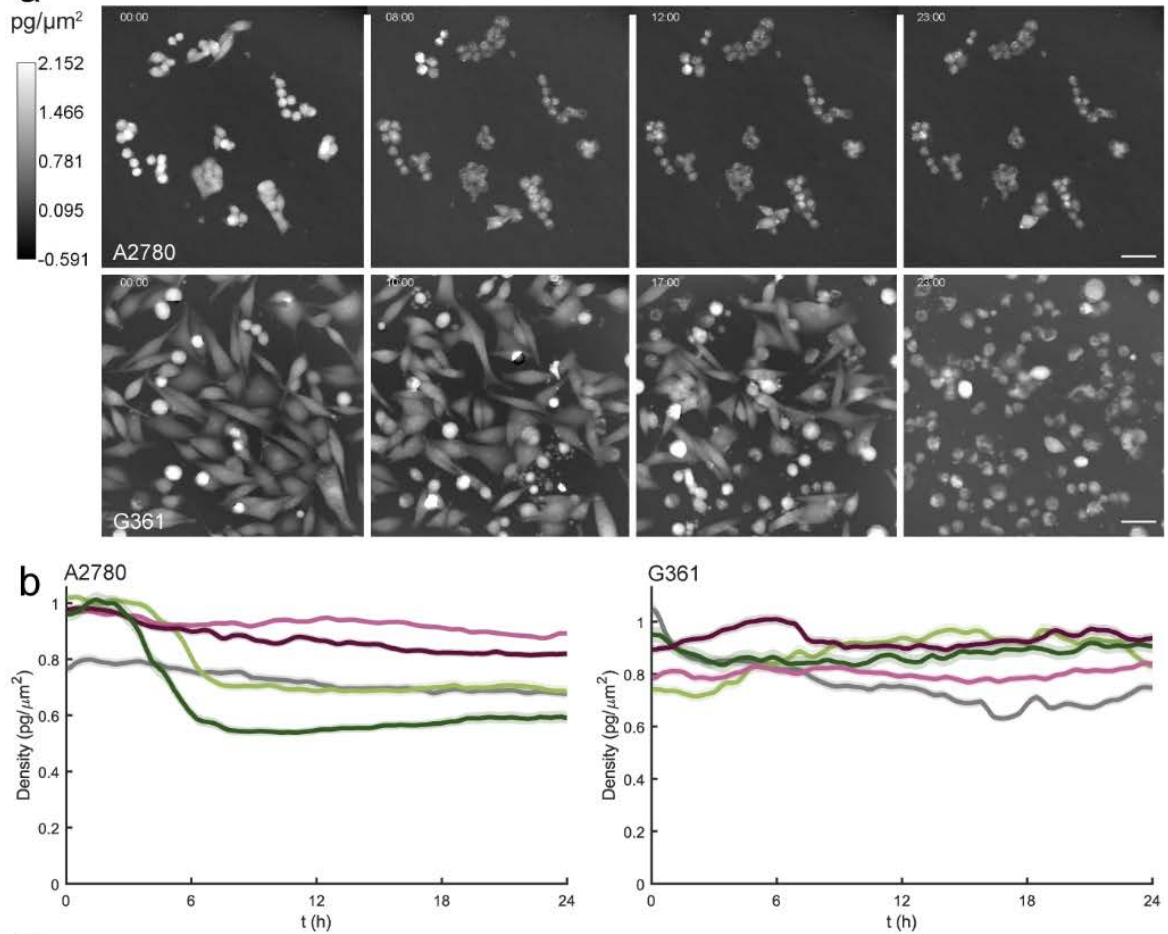

C $\quad$ A2780
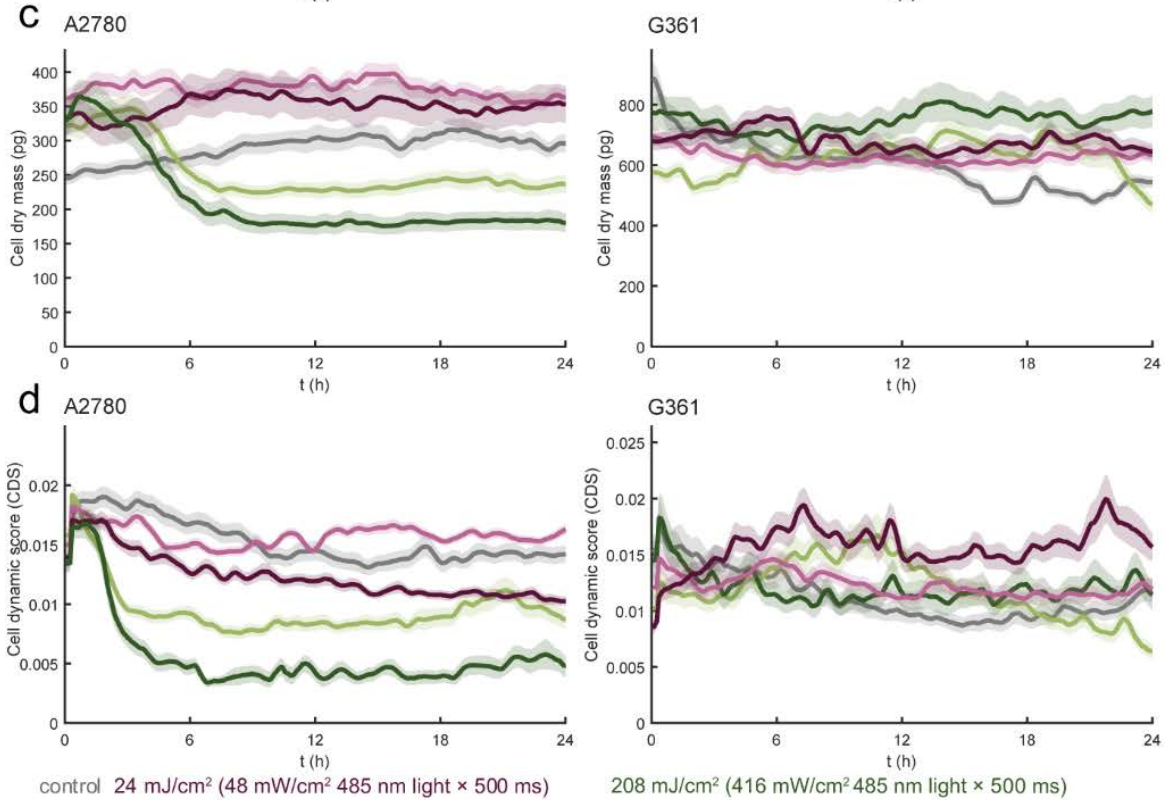

$24 \mathrm{~mJ} / \mathrm{cm}^{2}\left(24 \mathrm{~mW} / \mathrm{cm}^{2} 485 \mathrm{~nm}\right.$ light $\left.\times 1000 \mathrm{~ms}\right)$

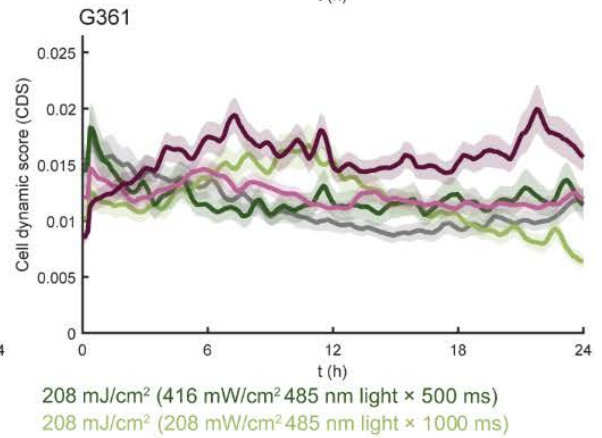

Figure 6. Quantitative phase-related parameters of dying A2780 and G361 cells. (a) Example of quantitative phase images for A2780 and G361 cells in different time-points under blue light dose $208 \mathrm{~mJ} / \mathrm{cm}^{2} \times 1000 \mathrm{~ms}$. Scale bar $=50 \mu \mathrm{m}(\mathbf{b})$ Real-time changes in cell density of A2780 and G361 cells during $24 \mathrm{~h}$ of the experiment. (c) Real-time changes in cell dry mass of A2780 and G361 cells during $24 \mathrm{~h}$ of the experiment. (d) Real-time changes in Cell Dynamic Score (CDS) of A2780 and G361 cells during $24 \mathrm{~h}$ of the experiment. CDS shows the average intensity change of cell pixels.

\section{Discussion}

Light emitters such as LEDs, TV and other electronics are presently used daily. Also, photodynamic therapy and fluorescence microscopy (FM) uses light to cause-effect on biological samples. Despite the widespread of FM in cell research, the effect of light on basic cell features was not well characterized yet. In this study, we evaluated the effect of blue light $(485 \mathrm{~nm})$ on cell parameters such as proliferation 
activity, cell motility, and cell mass in three human cancer cell lines (A2780, PC-3, G361) and one non-malignant human cell line (PNT1A) using MHM. The light doses in our study were 24 or $208 \mathrm{~mJ} / \mathrm{cm}^{2}$ and were achieved by a combination of two different times of expositions 500 and $1000 \mathrm{~ms}$ and specific light intensity (Figure 1). In the last 15 years, holographic microscopy hand in hand with advanced image analysis made significant progress to become a suitable technique for conducting label-free time-lapse experiments with biological specimens.

Our results show that blue light $208 \mathrm{~mJ} / \mathrm{cm}^{2} \times 1000 \mathrm{~ms}$ negatively affect malignant cell motility and does not change the motility of benign PNT1A cells. Phan et al. have described the positive effect of $470 \mathrm{~nm}$ light on the motility of T-cells. Enhanced motility may be caused by the $\mathrm{H}_{2} \mathrm{O}_{2}$ signaling pathway [1]. Our finding follows Oh et al., where authors concluded that blue light inhibits cell migration, thus invasivity of cancer cells. This may be mediated by the effect on MAPK and NF-kB activity and down-regulation of the ERK1/2 signaling pathway which leads to a decrease in protein expression of MMP-2 and MMP-9 [40]. On the other hand, Lan et al. postulated that blue light gradient could have an impact on cancer cell migration. According to their study, ROS production is proportional to light exposition. Cancer lung cells A549 exposed to $473 \mathrm{~nm}$ blue light gradient reported higher ROS production but also higher motility driven by increasing light gradient [41]. However, this study employed a gradient of light which may have a different effect on cells as the light dose on cells varied during the exposition. It was shown that blue light generates oxidative stress [42], induce cell damage and affects the gene expression [43].

Our results also show that blue light significantly affects cell proliferation, in most cases negatively. Although some light doses such as $24 \mathrm{~mJ} / \mathrm{cm}^{2} \times 500 \mathrm{~ms}$ in A2780 and PC-3 cells showed some proliferative effects these effects showed no statistical significance. Some proliferative effects of light have previously been described. Moore et al. registered a positive effect of light on the proliferation of endothelial cells and fibroblasts but those results are not comparable with our results since a low-intensity laser with wavelength $665 \mathrm{~nm}$ was used [44]. The higher light doses affect cell proliferation more than lower ones. The least harmful dose for our cells was $24 \mathrm{~mJ} / \mathrm{cm}^{2} \times 500 \mathrm{~ms}$, therefore this dose can be used for fluorescence microscopy of these cells. Oh et al. [45] described the reverse effect of light on cell proliferation, where blue light exposition leads to the activation of caspase- 3 and PARP inducing a caspase-dependent apoptotic pathway [45].

To correctly evaluate the effect of the blue light used in our experiment, it is necessary to correlate with cell mass distribution. Interestingly, the cell mass in A2780 decreased quickly after exposure to blue light dose $208 \mathrm{~mJ} / \mathrm{cm}^{2} \times 1000 \mathrm{~ms}$, whereas the cell mass in PC-3 increased. The increase of cell mass implies higher anabolic activity in the metastatic PC-3 cells, which can serve as a mechanism of survival in harmful conditions. As the number of PC-3 cells remains the same from the beginning of the experiment, cells were not undergoing cell death, as the results could suggest, but only suppress their proliferation activity. This finding supports a study from Gilchrest et al. which reports that UV light induces mitosis via the creation of protecting factors which may lead to avoiding apoptosis [46] and also Tolde at. el. indicate that changes in cell mass distribution may play a role in cell motility [47]. On the contrary, A2780 cells showed a significant decrease in cell mass even though the number of cells decreased only slightly. The disproportionality of these two parameters is evidence of cell death because the automatic algorithm of the MHM tracks also dead cells during the experiment as previously described in Vicar et al. [23]. This is following our observations where is evident that A2780 cells were killed during the first hours of the experiment (Supplementary Video S2).

Since QPI has recently been used for detection and classification of cell death $[16,22,23,48]$, based on these results, we hypothesized that light dose $208 \mathrm{~mJ} / \mathrm{cm}^{2} \times 1000 \mathrm{~ms}$ induce different types of cell death in A2780 and G361 cell lines. Based on the time-lapse videos (Supplementary Videos S2 and S4) and real-time quantitative parameters shown in Figure 6, it is evident that light dose $208 \mathrm{~mJ} \times 1000 \mathrm{~ms}$ induces specific changes in cell dry mass, CDS, and density in A2780 and G361 cells. For the A2780 cells, all three parameters steeply decreased in the first six hours of the experiment and remained low. The data correspond with the videos, as it shows that the effect of the light dose on A2780 cells 
is fast and cells are dead. The dead cells are still adherent to the surface with the disrupted plasma membrane and there is an absence of blebbing or releasing of apoptotic bodies. This may suggest the cells underwent necrosis as these parameters are characteristic for this type of cell death $[49,50]$. On the other hand, G361 cells show a stable slight increase in cell dry mass and density, which decreased in the last two hours. CDS decreased after eleven hours of the experiment. The results for G361, supported by the video (Supplementary Video S4), imply that cells underwent apoptosis. These cells showed gradual cell rounding and a loss of surface contact followed by intensive membrane blebbing. It corresponds with known facts describing morphological changes during apoptosis [51]. Recently, several studies have described the characterization of cell death based on cell morphology using quantitative phase imaging $[16,22,23,51]$. In particular, mapping of the quantitative phase changes during the time seems to be very promising in the determination of various morphological phenomena related to cell death, because the responsible cell death molecular machinery typically changes the distribution of the cell mass (cell content cleavage by caspases and loss of attachment during apoptosis connected with increased density; cell swelling during some kinds of lytic cell death—decrease in cell density) [23].

This study could also contribute to a better understanding of how light affects cells during fluorescence microscopy experiments, as the wavelength employed in our study is widely used. From our results, it is evident that cells were not damaged with the lower doses of light with a shorter time exposure. Thus, there is a need for low fluorescence doses and time exposures to achieve less destructive conditions for live samples during fluorescence microscopy. On the other hand, fluorescent microscopy always compromises between fluorescence damage to live samples and image quality.

\section{Conclusions}

Our results suggest that MHM within advanced image analysis is capable of correctly distinguishing between changes in cell motility, cell dry mass, cell density, and cell death induced by blue light. As quantitative phase dynamics of a cell population is typical for specific processes in cells, it may be useful for viability tests and medical drugs evaluation. We have also shown that specific doses of blue light significantly influence cell motility, cell dry mass, and cell density. These changes seem to be specific for the particular cell line and the malignant status of tested cells. Based on the dynamics of QPI parameters, we assume that light dose $208 \mathrm{~mJ} / \mathrm{cm}^{2} \times 1000 \mathrm{~ms}$ induced different types of cell death in A2780 and G361 cell lines.

Supplementary Materials: The following are available online at http://www.mdpi.com/2076-3417/10/7/2597/s1. Supplementary Videos S1-S4. Quantitative phase image dataset used in the manuscript is available at Zenodo repository (www.zenodo.org), https://doi.org/10.5281/zenodo.3670966 (PC-3 and PNT1A cells), https://doi.org/10. 5281/zenodo.3673425 (A2780 and G361 cells).

Author Contributions: Conceptualization, J.B.; Methodology, M.F. and J.B.; Software, M.F. and J.B.; Data curation, T.V. and J.G.; Formal analysis, M.R. and J.B.; Writing-Original Draft Preparation, M.F.; Writing-Review and Editing, M.R., A.G.W. and J.B.; Visualization, M.F., J.G., T.V. and J.B.; Supervision, J.B.; Project Administration, J.B. and M.M.; Funding Acquisition, J.B. All authors have read and agreed to the published version of the manuscript.

Funding: This work was supported by funds from the Faculty of Medicine, Masaryk University to Junior researcher (Jan Balvan), by Grant Agency of the Czech Republic (18-24089S), European Union's Horizon 2020 research and innovation program under the Marie Sklodowska-Curie grant agreement No 721297, Biofilms Research Center for Biointerfaces, and Malmö University and by the "Center for Tumor Ecology-Research of the Cancer Microenvironment Supporting Cancer Growth and Spread" (reg. no. CZ.02.1.01/0.0/0.0/16_019/0000785) supported by the Operational Program Research, Development and Education.

Acknowledgments: We acknowledge Telight, a.s. for support to Telight Q-PHASE technology.

Conflicts of Interest: The authors declare no conflict of interest.

\section{References}

1. Phan, T.X. Intrinsic Photosensitivity Enhances Motility of T Lymphocytes. Sci. Rep. 2016, 6, 39479. [CrossRef] [PubMed] 
2. Lewis, J.B. Blue light differentially alters cellular redox properties. J. Biomed. Mater. Res. Part B Appl. Biomater. 2005, 72, 223-229. [CrossRef] [PubMed]

3. Omata, Y. Intra- and extracellular reactive oxygen species generated by blue light. J. Biomed. Mater. Res. Part A 2006, 77, 470-477. [CrossRef] [PubMed]

4. Chotikasemsri, P.; Tangtrakulwanich, B.; Sangkhathat, S. The Effect of Phototherapy on Cancer Predisposition Genes of Diabetic and Normal Human Skin Fibroblasts. Biomed Res. Int. 2017, 2017, 7604861. [CrossRef]

5. Winkler, B.S. Oxidative damage and age-related macular degeneration. Mol. Vis. 1999, 5, 32.

6. Kuse, Y. Damage of photoreceptor-derived cells in culture induced by light emitting diode-derived blue light. Sci. Rep. 2014, 4, 5223. [CrossRef]

7. Osborne, N.N.; Nunez-Alvarez, C.; del Olmo-Aguado, S. The effect of visual blue light on mitochondrial function associated with retinal ganglions cells. Exp. Eye Res. 2014, 128, 8-14. [CrossRef]

8. Triesscheijn, M. Photodynamic therapy in oncology. Oncologist 2006, 11, 1034-1044. [CrossRef]

9. Ochsner, M. Photophysical and photobiological processes in the photodynamic therapy of tumours. J. Photochem. Photobiol. B-Biol. 1997, 39, 1-18. [CrossRef]

10. Sullivan, R.M. Photo-induced inactivation of protein kinase $C$ alpha by dequalinium inhibits motility of murine melanoma cells. Mol. Pharmacol. 2000, 58, 729-737. [CrossRef]

11. Petty, H.R. Fluorescence microscopy: Established and emerging methods, experimental strategies, and applications in immunology. Microsc. Res. Tech. 2007, 70, 687-709. [CrossRef]

12. Sanderson, M.J. Fluorescence Microscopy. Cold Spring Harb. Protoc. 2014, 2014, pdb.top071795-p. [CrossRef] [PubMed]

13. Slaby, T. Off-axis setup taking full advantage of incoherent illumination in coherence-controlled holographic microscope. Opt. Express 2013, 21, 14747-14762. [CrossRef] [PubMed]

14. Miniotis, M.F.; Mukwaya, A.; Wingren, A.G. Digital Holographic Microscopy for Non-Invasive Monitoring of Cell Cycle Arrest in L929 Cells. PLoS ONE 2014, 9, e106546.

15. Sebesta, M. HoloMonitor M4: Holographic imaging cytometer for real-time kinetic label-free live-cell analysis of adherent cells. In Proceedings of the 2nd Conference on Quantitative Phase Imaging (QPI II), San Francisco, CA, USA, 14-17 February 2016; Spie-Int Soc Optical Engineering: San Francisco, CA, USA, 2016.

16. El-Schich, Z. Induction of morphological changes in death-induced cancer cells monitored by holographic microscopy. J. Struct. Biol. 2015, 189, 207-212. [CrossRef]

17. Kemper, B. Multimodal label-free growth and morphology characterization of different cell types in a single culture with quantitative digital holographic phase microscopy. In Proceedings of the 1st Conference on Quantitative Phase Imaging (QPI), San Francisco, CA, USA, 7-9 February 2015; Spie-Int Soc Optical Engineering: San Francisco, CA, USA, 2015.

18. Fojtu, M. Black Phosphorus Cytotoxicity Assessments Pitfalls: Advantages and Disadvantages of Metabolic and Morphological Assays. Chem.-A Eur. J. 2019, 25, 349-360. [CrossRef]

19. Park, Y.; Depeursinge, C.; Popescu, G. Quantitative phase imaging in biomedicine. Nat. Photonics 2018, 12, 578-589. [CrossRef]

20. Chmelik, R. Chapter 5-The Role of Coherence in Image Formation in Holographic Microscopy. In Progress in Optics; Wolf, E., Ed.; Elsevier: Amsterdam, The Netherlands, 2014; pp. 267-335.

21. Shaffer, E.; Pavillon, N.; Depeursinge, C. Single-shot, simultaneous incoherent and holographic microscopy. J. Microsc. 2012, 245, 49-62. [CrossRef]

22. Balvan, J. Multimodal Holographic Microscopy: Distinction between Apoptosis and Oncosis. PLoS ONE 2015, 10, e0121674. [CrossRef]

23. Vicar, T. The Quantitative-Phase Dynamics of Apoptosis and Lytic Cell Death. Sci. Rep. 2020, $10,1566$. [CrossRef]

24. Yu, X. Four-dimensional motility tracking of biological cells by digital holographic microscopy. J. Biomed. Opt. 2014, 19, 045001. [CrossRef]

25. Wingren, A.G. Moving into a new dimension: Tracking migrating cells with digital holographic cytometry in 3D. Cytom. Part A 2019, 95, 144-146. [CrossRef] [PubMed]

26. Mitchell, S. Phenotypic and genotypic characterization of commonly used human prostatic cell lines. BJU Int. 2000, 85, 932-944. [CrossRef] [PubMed]

27. Sharrard, R.M.; Maitland, N.J. Regulation of Protein Kinase B activity by PTEN and SHIP2 in human prostate-derived cell lines. Cell. Signal. 2007, 19, 129-138. [CrossRef] [PubMed] 
28. Schmieg, F.I.; Simmons, D.T. Characterization of the Invitro Interaction between Sv40 T-Antigen and P53-Mapping the P53 Binding-Site. Virology 1988, 164, 132-140. [CrossRef]

29. Kreis, T. Digital Holographic Interference-Phase Measurement Using the Fourier-Transform Method. J. Opt. Soc. Am. A-Opt. Image Sci. Vis. 1986, 3, 847-855. [CrossRef]

30. Goldstein, R.M.; Zebker, H.A.; Werner, C.L. Satellite Radar Interferometry-Two-Dimensional Phase Unwrapping. Radio Sci. 1988, 23, 713-720. [CrossRef]

31. Ghiglia, D.C.; Pritt, M.D. Two-Dimensional Phase Unwrapping: Theory, Algorithms, and Software; Wiley: Hoboken, NJ, USA, 1998.

32. Prescher, J.A.; Bertozzi, C.R. Chemistry in living systems. Nat. Chem. Biol. 2005, 1, 13-21. [CrossRef]

33. Loewke, N.O. Automated Cell Segmentation for Quantitative Phase Microscopy. IEEE Trans. Med. Imaging 2018, 37, 929-940. [CrossRef]

34. Chalfoun, J. Empirical gradient threshold technique for automated segmentation across image modalities and cell lines. J. Microsc. 2015, 260, 86-99. [CrossRef]

35. Vicar, T. Cell segmentation methods for label-free contrast microscopy: Review and comprehensive comparison. BMC Bioinform. 2019, 20, 360. [CrossRef] [PubMed]

36. Meyer, F. Topographic distance and watershed lines. Signal Process. 1994, 38, 113-125. [CrossRef]

37. Maurer, C.R.; Qi, R.S.; Raghavan, V. A linear time algorithm for computing exact Euclidean distance transforms of binary images in arbitrary dimensions. IEEE Trans. Pattern Anal. Mach. Intell. 2003, 25, $265-270$. [CrossRef]

38. R Core Team. R: A Language and Environment for Statistical Computing; R Foundation for Statistical Computing: Vienna, Austria, 2019.

39. Kassambara, A. Ggpubr: 'ggplot2' Based Publication Ready Plots; R Package Version 0.2.4; 2019.

40. Oh, P.-S. Inhibitory effect of blue light emitting diode on migration and invasion of cancer cells. J. Cell. Physiol. 2017, 232, 3444-3453. [CrossRef] [PubMed]

41. Lan, C.C. Directional migration of cancer cells induced by a blue light intensity gradient. Biomed. Opt. Express 2015, 6, 2624-2632. [CrossRef] [PubMed]

42. Nakashima, Y.; Ohta, S.; Wolf, A.M. Blue light-induced oxidative stress in live skin. Free Radic. Biol. Med. 2017, 108, 300-310. [CrossRef]

43. Nash, T.R. Daily blue-light exposure shortens lifespan and causes brain neurodegeneration in Drosophila. NPJ Aging Mech. Dis. 2019, 5, 8. [CrossRef]

44. Moore, P. Effect of wavelength on low-intensity laser irradiation-stimulated cell proliferation in vitro. Lasers Surg. Med. 2005, 36, 8-12. [CrossRef]

45. Oh, P.-S. Effect of blue light emitting diodes on melanoma cells: Involvement of apoptotic signaling. J. Photochem. Photobiol. B Biol. 2015, 142, 197-203. [CrossRef]

46. Gilchrest, B.A. Mechanisms of Ultraviolet Light-Induced Pigmentation. Photochem. Photobiol. 1996, 63, 1-10. [CrossRef]

47. Tolde, O. Quantitative phase imaging unravels new insight into dynamics of mesenchymal and amoeboid cancer cell invasion. Sci. Rep. 2018, 8, 12020. [CrossRef] [PubMed]

48. Khmaladze, A. Cell volume changes during apoptosis monitored in real time using digital holographic microscopy. J. Struct. Biol. 2012, 178, 270-278. [CrossRef] [PubMed]

49. Trump, B.F. The pathways of cell death: Oncosis, apoptosis, and necrosis. Toxicol. Pathol. 1997, 25, 82-88. [CrossRef] [PubMed]

50. Edinger, A.L.; Thompson, C.B. Death by design: Apoptosis, necrosis and autophagy. Curr. Opin. Cell Biol. 2004, 16, 663-669. [CrossRef]

51. Rello, S. Morphological criteria to distinguish cell death induced by apoptotic and necrotic treatments. Apoptosis 2005, 10, 201-208. [CrossRef]

(C) 2020 by the authors. Licensee MDPI, Basel, Switzerland. This article is an open access article distributed under the terms and conditions of the Creative Commons Attribution (CC BY) license (http://creativecommons.org/licenses/by/4.0/). 